\title{
Local Transmission of Zika Virus - Puerto Rico, November 23, 2015-January 28, 2016
}

\author{
Dana L. Thomas, MD ${ }^{1,2}$; Tyler M. Sharp, $\mathrm{PhD}^{3}$; Jomil Torres, $\mathrm{MS}^{1}$; Paige A. Armstrong, $\mathrm{MD}^{4}$; Jorge Munoz-Jordan, PhD 3 ; Kyle R. Ryff, MPH ${ }^{1}$; \\ Alma Martinez-Quiñones, $\mathrm{MPH}^{5}$; José Arias-Berríos, $\mathrm{MD}^{6}$; Marrielle Mayshack ${ }^{1,7}$; Glenn J. Garayalde, $\mathrm{MD}^{8}$; Sonia Saavedra, $\mathrm{MD}$, $\mathrm{PhD}^{8}$; \\ Carlos A. Luciano, MD ${ }^{6}$; Miguel Valencia-Prado ${ }^{5}$; Steve Waterman, $\mathrm{MD}^{3}$; Brenda Rivera-García, DVM ${ }^{1}$
}

\begin{abstract}
On February 12, 2016, this report was posted as an MMWR Early Release on the MMWR website (http://www.cdc.gov/mmwr).
\end{abstract}

Zika virus, a mosquito-borne flavivirus, spread to the Region of the Americas (Americas) in mid-2015, and appears to be related to congenital microcephaly and Guillain-Barré syndrome $(1,2)$. On February 1, 2016, the World Health Organization (WHO) declared the occurrence of microcephaly cases in association with Zika virus infection to be a Public Health Emergency of International Concern.* On December 31, 2015, Puerto Rico Department of Health (PRDH) reported the first locally acquired (index) case of Zika virus disease in a jurisdiction of the United States in a patient from southeastern Puerto Rico. During November 23, 2015January 28, 2016, passive and enhanced surveillance for Zika virus disease identified 30 laboratory-confirmed cases. Most (93\%) patients resided in eastern Puerto Rico or the San Juan metropolitan area. The most frequently reported signs and symptoms were rash (77\%), myalgia (77\%), arthralgia (73\%), and fever (73\%). Three (10\%) patients were hospitalized. One case occurred in a patient hospitalized for Guillain-Barré syndrome, and one occurred in a pregnant woman. Because the most common mosquito vector of Zika virus, Aedes aegypti, is present throughout Puerto Rico, Zika virus is expected to continue to spread across the island. The public health response in Puerto Rico is being coordinated by PRDH with assistance from CDC. Clinicians in Puerto Rico should report all cases of microcephaly, Guillain-Barré syndrome, and suspected Zika virus disease to $\mathrm{PRDH}$. Other adverse reproductive outcomes, including fetal demise associated with Zika virus infection, should be reported to PRDH. To avoid infection with Zika virus, residents of and visitors to Puerto Rico, particularly pregnant women, should strictly follow steps to avoid mosquito bites, including wearing pants and long-sleeved shirts, using permethrin-treated clothing and gear, using an Environmental Protection Agency (EPA)-registered insect repellent, and ensuring that windows and doors have intact screens.

In November 2015, PRDH, with assistance from CDC, initiated surveillance for Zika virus disease in Puerto Rico by modifying the existing Passive Dengue Surveillance System (3) to include suspected Zika virus disease. Patients in whom a

*http://www.cdc.gov/zika. clinician suspected Zika virus disease were reported by sending a serum specimen with a modified dengue case investigation form. ${ }^{\dagger}$ In January 2016, PRDH initiated enhanced surveillance for Zika virus disease by performing Zika virus testing on specimens submitted during November 2015-January 2016 that had tested negative for dengue or chikungunya.

Specimens collected within 7 days of illness onset were tested by reverse transcription-polymerase chain reaction (RT-PCR) with updated primers to detect Zika virus RNA. Specimens collected $\geq 4$ days after illness onset were tested by immunoglobulin M (IgM) capture enzyme-linked immunosorbent assay (ELISA) to detect serologic evidence of recent Zika virus infection. Laboratory-confirmed Zika virus disease cases were defined as detection of either Zika virus RNA by RT-PCR, or anti-Zika virus IgM antibody by ELISA with a simultaneous negative anti-dengue virus IgM antibody test.

\section{Epidemiology and Laboratory Investigations}

During November 23, 2015-January 28, 2016, a total of 155 suspected Zika virus disease cases were identified in Puerto Rico, including 82 reported through passive surveillance, and 73 specimens tested through the enhanced surveillance protocol. Overall, 30 (19\%) cases had laboratory confirmation of Zika virus disease. Among these cases, one (3\%) patient had reported illness onset in November 2015 (the index patient), eight (27\%) in December 2015, and 21 (70\%) in January 2016. One patient with illness onset in late December reported travel to the Dominican Republic within 14 days of illness onset.

After identification of the index case, two cases were detected during the first 2 weeks of December; six cases per week were reported during the 2nd and 3rd weeks of 2016 (Figure 1). Patients resided in municipalities throughout eastern Puerto Rico and the San Juan metropolitan area, and one each resided in Ponce and Guánica (Figure 2). The most frequently reported symptoms were rash, myalgia, arthralgia, and fever (Table). Fever, rash, arthralgia, and conjunctivitis were reported in seven $(23 \%)$ patients. Coinfection with influenza B virus was reported in one patient. Three $(10 \%)$ patients were hospitalized: the index patient, one patient with Guillain-Barré

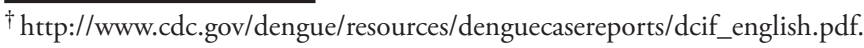


syndrome, and another patient who was hospitalized because of thrombocytopenia and clinical suspicion of dengue.

Index case. The first case of Zika virus disease identified in Puerto Rico occurred in a man aged 80 years from southeastern Puerto Rico with multiple chronic medical conditions, who reported onset of symptoms on November 23, 2015. Eight days after illness onset, he was evaluated in a hospital emergency department for progressive weakness after several days of watery, nonbloody diarrhea, recent episodes of falling, shoulder pain, chills, malaise, and abdominal pain. He did not report myalgia, headache, or retro-orbital pain. He was febrile, tachycardic, tachypneic, and hypotensive, with bilateral erythematous sclera. Laboratory results revealed leukocytosis with a predominance of neutrophils; hemoconcentration; thrombocytopenia; elevated serum transaminases, blood urea nitrogen, and creatinine; hyponatremia; and hypoglycemia. He received a diagnosis of sepsis, was admitted to the intensive care unit for fluid resuscitation and monitoring, and was treated with broad spectrum antibiotics. Diagnostic considerations included leptospirosis and dengue. He experienced respiratory decompensation requiring intubation and 5 days of mechanical ventilation. He was hospitalized for 2 weeks, during which time he underwent an extensive evaluation. Blood and stool cultures were negative, as were serologic tests for human immunodeficiency virus, Leptospira, and Strongyloides. Schistosoma immunoglobulin $\mathrm{G}$ titers were elevated, for which praziquantel was administered. On December 2, serum was collected for dengue and chikungunya diagnostic testing, and was positive for anti-dengue virus $\operatorname{IgM}$, negative for anti-chikungunya virus $\operatorname{IgM}$, and negative for detection of dengue virus and chikungunya virus RNA. Because a hospital-based enhanced surveillance protocol was in place for detection of Zika virus, the same serum specimen was tested for Zika virus infection by RT-PCR with a positive result. Confirmatory molecular diagnostic testing was performed at CDC. Detection of antidengue virus IgM antibody likely was a result of cross-reactive anti-Zika virus IgM antibody. Although no pathogen other than Zika virus was identified, the patient's clinical course suggests that he also had an occult bacterial infection.

\section{Selected Additional Patients' Characteristics}

Case A. On January 13, 2016, a man aged 37 years developed a rash, which resolved over the next 2 days; the next day, he noted paresthesias in his hands and feet, followed by progressive weakness in bulbar and limb muscles and uncontrolled fluctuating hypertension consistent with dysautonomia. On medical evaluation he had bilateral facial weakness, weakness in the upper and lower limbs, and areflexia, and was hospitalized for ascending paralysis. Cerebrospinal fluid protein was elevated, and electrodiagnostic studies showed evidence of a demyelinating polyneuropathy, consistent with the acute inflammatory demyelinating polyneuropathy variant of Guillain-Barré syndrome. The patient responded to treatment with intravenous immunoglobulin. A serum specimen collected 15 days after illness onset, and before administration of intravenous immunoglobulin, was positive for anti-Zika virus IgM antibody, negative for anti-dengue IgM antibody, and negative for Zika, dengue, and chikungunya virus RNA by RT-PCR. A urine specimen collected 19 days after illness onset was also negative for Zika virus RNA by RT-PCR. This is the only patient in Puerto Rico with Guillain-Barré syndrome and confirmed Zika virus disease identified to date.

Case B. On January 22, 2016, RT-PCR-confirmed Zika virus disease was diagnosed in a woman in her first trimester of pregnancy; she had sought care because of a 2-day history of nonfebrile eye, body, and joint pain; petechial rash; conjunctivitis; and nausea. Her obstetrician provided counseling regarding risks to her fetus and recommended clinical followup, according to CDC interim guidelines (4).

\section{Public Health Response}

The public health response has focused on educating clinicians and the public, establishing laboratory capacity, improving epidemiologic capacity for detecting and monitoring all laboratory-confirmed cases of Zika virus disease in pregnant women, and reducing risk for infection to women who are pregnant. Community cleanup campaigns are being organized throughout the island to remove standing water from containers where Aedes aegypti mosquitos might breed. Additional approaches to effective and sustainable mosquito control are being considered.

No cases of microcephaly potentially associated with Zika virus infection have been reported to PRDH. Because microcephaly was not previously captured through routine surveillance, retrospective medical record review of live births during 2013-2015 will be conducted to define the baseline annual incidence of congenital microcephaly among live births, as defined by head circumference below the third percentile for sex and gestational age (5). The Puerto Rico Birth Defects Surveillance and Prevention System (BDSPS) case definition has been modified to capture microcephaly cases not associated with another major birth defect of the central nervous system. Clinicians in Puerto Rico have been advised to report all cases of congenital microcephaly to the BDSPS. PRDH, with assistance from CDC, will maintain a registry of all pregnant women with laboratory-confirmed Zika virus infection, who will be followed throughout their pregnancy.

Guillain-Barré syndrome is not a reportable condition in the United States, including Puerto Rico. In conjunction with neurologists in Puerto Rico, a Guillain-Barré syndrome surveillance 
FIGURE 1. Zika virus disease cases* $(\mathrm{N}=30)$, by week of onset of patient's illness — Puerto Rico, November 23, 2015-January 28, 2016

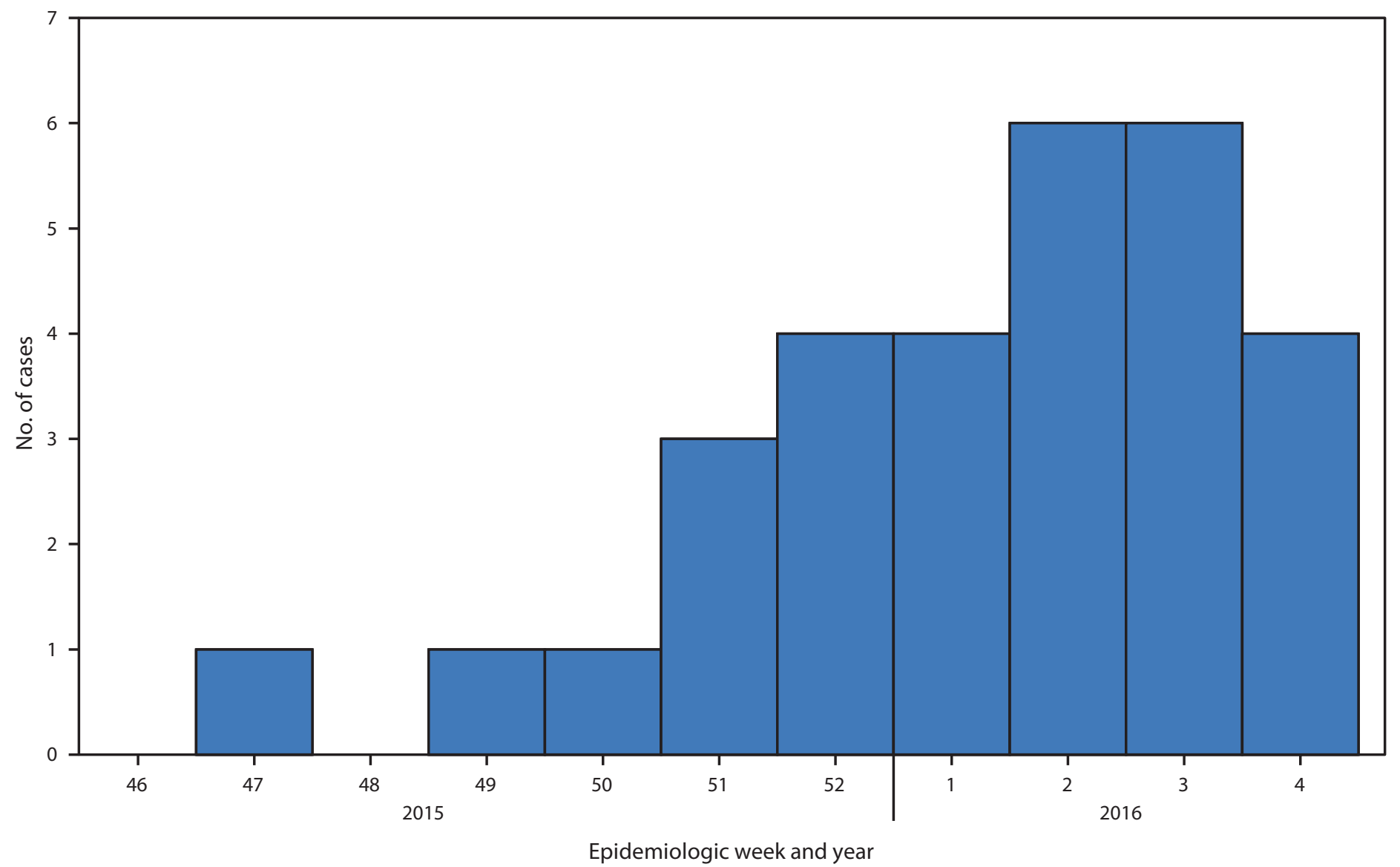

* All cases laboratory-confirmed, Dengue Branch, CDC.

system is being established to identify cases of clinically diagnosed Guillain-Barré syndrome. After identification of a case of clinically confirmed Guillain-Barré syndrome, testing for arboviral and other infections will be performed. Cases of Guillain-Barré syndrome will be further investigated to define the association between Zika virus infection and Guillain-Barré syndrome.

Because of reports of detection of Zika virus RNA in saliva and urine $(6,7)$, as well as reports of sexual transmission of Zika virus $(8,9)$, patients with laboratory-confirmed Zika virus infection will be followed to determine the persistence of Zika virus RNA, as well as the presence of infectious virus in saliva, urine, and semen.

\section{Discussion}

In May 2015, WHO reported the first local transmission of Zika virus in the Americas in Brazil (10). As of February 3, 2016 , local transmission of Zika virus has been reported in 26 countries and territories in the Caribbean and South and Central America. $\$$

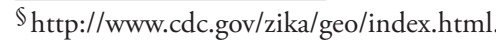

The cases described in this report are the first documented local transmission of Zika virus in a jurisdiction of the United States. Aedes aegypti, the most common mosquito vector of $\mathrm{Zika}$ virus worldwide, is present throughout Puerto Rico. Therefore, Zika virus is expected to continue to spread throughout the territory, and the 3.5 million residents of Puerto Rico, including approximately 43,000 pregnant women per year, are at risk for Zika virus infection.

Approximately $80 \%$ of Zika virus infections are asymptomatic (11). The most common symptoms reported by patients in Puerto Rico with laboratory-confirmed Zika virus disease were rash, body and joint pain, and fever. Approximately 25\% of patients reported all of the signs and symptoms most commonly associated with Zika virus disease: fever, rash, arthralgia, and conjunctivitis (11). This suggests a variable clinical presentation in patients with Zika virus disease. Whether these signs and symptoms are reflective of all persons with symptomatic Zika virus infection, or represent patients with more severe disease, is unknown, as these patients had all sought medical care. This bias might be reflected in the observed rate of patient hospitalization, which was higher than expected on the 


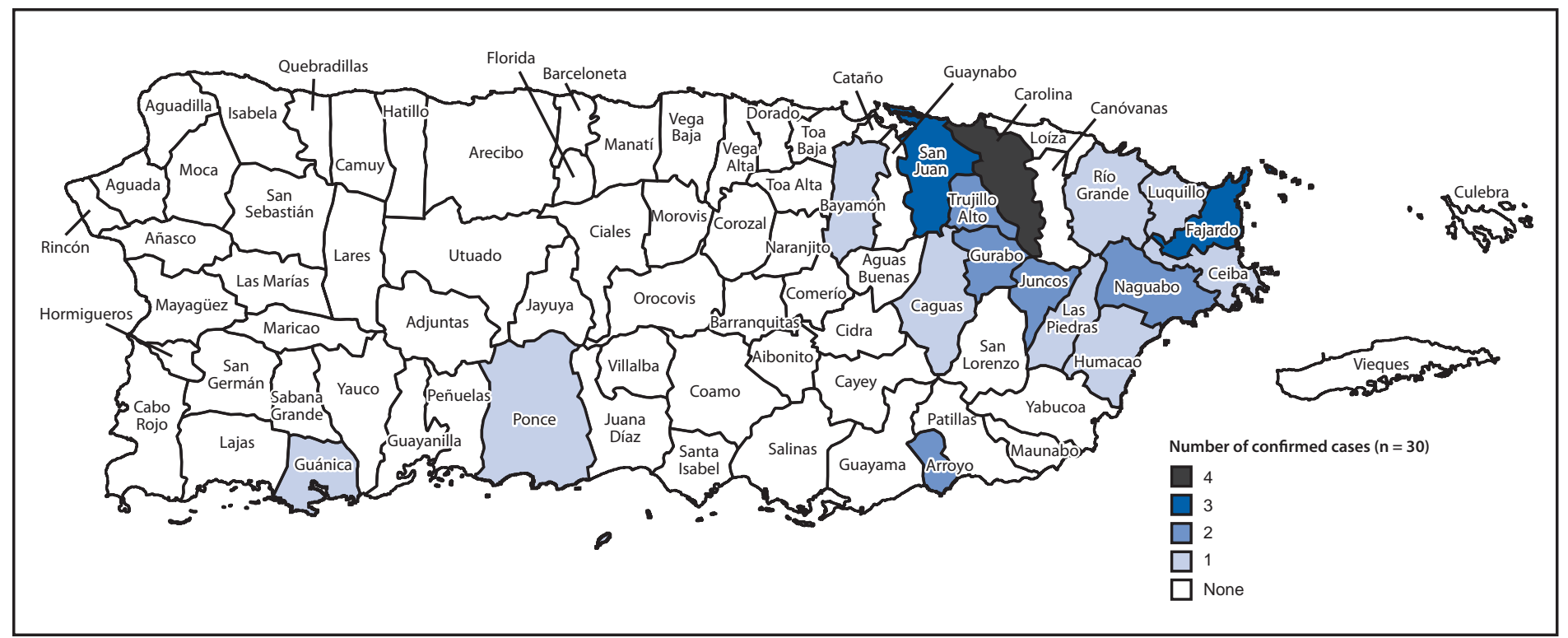

* All cases laboratory-confirmed, Dengue Branch, CDC.

† Total number of cases $=30 ; 1$ case not shown because location unknown; 1 case in Juncos was travel-associated.

$\S$ Data current as of February 11, 2016.

basis of previous reports (11). Because symptomatic persons with less severe Zika virus disease might not have sought care, the cases reported here might underestimate the incidence of symptomatic Zika virus infection in Puerto Rico.

Clinicians in Puerto Rico should report all patients with fever, joint pain, rash, or conjunctivitis to $\mathrm{PRDH}$ as a suspected case of Zika virus disease if another etiology has not been identified. All patients with suspected dengue, chikungunya, or Zika virus disease from whom a specimen has been collected during the first 6 days of illness will be tested by PRDH with an assay currently under development at CDC that simultaneously tests for Zika, chikungunya, and dengue virus RNA. Because of possible complications associated with dengue, including increased vascular permeability that might lead to shock and hemorrhage, patients with suspected Zika, dengue, or chikungunya should be managed as dengue patients until another diagnosis is established. Clinicians in Puerto Rico should also be aware of currently ongoing influenza virus transmission at epidemic levels, ${ }^{* *}$ and consider influenza in the differential diagnosis when evaluating patients with acute febrile illness. Current case counts of laboratory-confirmed Zika virus disease cases are available online. ${ }^{\dagger \dagger}$

\footnotetext{
Dengue clinical case management online training course (http://www.cdc. gov/dengue/training/cme.html).

** http://www.salud.gov.pr/Estadisticas-Registros-y-Publicaciones/Pages/ Influenza.aspx.

$\dagger^{\dagger}$ http://www.salud.gov.pr/Estadisticas-Registros-y-Publicaciones/Pages/ Informe-Arboviral.aspx.
}

Currently, no medication or vaccine is available to treat or prevent Zika virus disease. To prevent infection, persons residing in affected areas or traveling to areas of active Zika virus transmission should strictly follow steps to avoid mosquito bites. Men who reside in or have traveled to an area of active Zika virus transmission who have a pregnant partner should abstain from sexual activity or consistently and correctly use condoms during sex, and men who reside in or have traveled to an area of active Zika virus transmission who are concerned about sexual transmission of Zika virus might consider abstaining from sexual activity or using condoms consistently and correctly during sex. ${ }^{\$ \$}$ Mosquito-bite prevention includes using air conditioning or window and door screens when indoors, wearing long sleeves and pants, using permethrin-treated clothing and gear, and using insect repellents. When used according to the product label, EPA-registered insect repellents are safe for pregnant women.99 Residents of Puerto Rico should cover, empty, or discard water containers that might serve as mosquito breeding sites (e.g., tires, plastic containers, and water cisterns). $\mathrm{PRDH}, \mathrm{CDC}$, and other partner organizations are urgently implementing broader plans for mosquito control and reduction of risk for Zika virus infection among pregnant women.

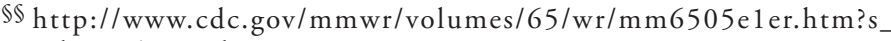
cid=mm6505e1.htm_w.

99 http://www.cdc.gov/Features/stopmosquitoes/index.html.
} 
TABLE. Demographic characteristics, clinical course, and signs and symptoms in 30 patients with Zika virus disease identified by the Puerto Rico Department of Health - Puerto Rico, November 23, 2015-January 28, 2016

\begin{tabular}{lcc}
\hline & \multicolumn{2}{c}{ Patients } \\
\cline { 2 - 3 } Characteristic & $\begin{array}{c}\text { Age/llness onset } \\
\text { (range) }\end{array}$ & No. (\%) \\
\hline Median age (yrs) & $40(10-80)$ & \\
Median time from illness onset to & $3(0-15)$ & \\
$\quad$ Histocimen collection (days) & & $1(3)$ \\
Female & $18(60)$ \\
Pregnant & $1(3)$ \\
Hospitalized & $3(10)$ \\
Signs and symptoms ${ }^{\dagger}$ & \\
Rash & & $23(77)$ \\
Myalgia & $23(77)$ \\
Arthralgia & $22(73)$ \\
Fever & $22(73)$ \\
Eye pain & $20(67)$ \\
Chills & $20(67)$ \\
Headache & $19(63)$ \\
Sore throat & $12(40)$ \\
Petechiae & $10(33)$ \\
Conjunctivitis & $8(27)$ \\
Diarrhea & $7(23)$ \\
Nausea/Vomiting & $5(17)$ \\
\hline
\end{tabular}

* Travel outside of Puerto Rico and the United States in the 14 days before illness onset.

† Signs and symptoms were reported by the patients' clinician.

${ }^{1}$ Office of Epidemiology, Puerto Rico Department of Health; ${ }^{2}$ Division of State Laboratory Readiness, Office of Public Health Preparedness and Response, CDC; ${ }^{3}$ Division of Vector-Borne Diseases, National Center for Emerging and Zoonotic Infectious Diseases, CDC; ${ }^{4}$ Epidemic Intelligence Service, CDC;

${ }^{5}$ Puerto Rico Birth Defects Surveillance and Prevention System, Puerto Rico Department of Health; ${ }^{6}$ Department of Neurology, University of Puerto Rico School of Medicine; ${ }^{7}$ Office for State, Tribal, Local and Territorial Support, CDC; ${ }^{8}$ Veterans' Affairs Caribbean Healthcare System.

Corresponding author: Dana Thomas, Zika@salud.gov.pr, 787-265-2929.

\section{References}

1. Pan American Health Organization. Epidemiological alert: neurological syndrome, congenital malformations, and Zika virus infection. Implications for public health in the Americas. Washington, DC: World Health Organization, Pan American Health Organization; 2015. http:// www.paho.org/hq/index.php?option=com_docman\&task=doc_downl oad \&Itemid $=\&$ gid $=32405 \&$ lang $=$ en .

2. European Centres for Disease Control and Prevention. Zika virus epidemic in the Americas: potential association with microcephaly and Guillain-Barré syndrome. Stockholm, Sweden: European Centre for Disease Prevention and Control; 2015. http://ecdc.europa.eu/en/ publications/Publications/zika-virus-rapid-risk-assessment-8february-2016.pdf.

3. Noyd DH, Sharp TM. Recent advances in dengue: relevance to Puerto Rico. P R Health Sci J 2015;34:65-70.

\section{Summary}

What is already known about this topic?

Zika virus emerged in the Region of the Americas in mid-2015, and since then outbreaks have occurred in multiple South American and Caribbean countries and territories. Zika virus infection appears to be related to increased risk for fetal microcephaly and Guillain-Barré syndrome.

What is added by this report?

The first locally acquired case of Zika virus disease in Puerto Rico was identified in early December 2015. During the subsequent months, 29 additional laboratory-confirmed cases have been detected, including in one pregnant woman and in a man with Guillain-Barré syndrome.

What are the implications for public health practice?

Clinicians in Puerto Rico and other clinicians evaluating patients with recent travel to Puerto Rico should report all cases of suspected Zika virus disease to public health authorities. Residents of and visitors to Puerto Rico should strictly follow steps to avoid mosquito bites including using air conditioning or window and door screens when indoors, wearing long sleeves and pants, using permethrin-treated clothing and gear, and using insect repellents. When used according to the product label, Environmental Protection Agency-registered insect repellents are safe for pregnant women.

4. Petersen EE, Staples JE, Meaney-Delman D, et al. Interim guidelines for pregnant women during a Zika virus outbreak-United States, 2016. MMWR Morb Mortal Wkly Rep 2016;65:30-3. http://dx.doi. org/10.15585/mmwr.mm6502e1.

5. Staples JE, Dziuban EJ, Fischer M, et al. Interim guidelines for the evaluation and testing of infants with possible congenital Zika virus infection-United States, 2016. MMWR Morb Mortal Wkly Rep 2016;65:63-7. http://dx.doi.org/10.15585/mmwr.mm6503e3.

6. Musso D, Roche C, Nhan TX, Robin E, Teissier A, Cao-Lormeau VM. Detection of Zika virus in saliva. J Clin Virol 2015;68:53-5. http:// dx.doi.org/10.1016/j.jcv.2015.04.021.

7. Gourinat AC, O'Connor O, Calvez E, Goarant C, Dupont-Rouzeyrol M. Detection of Zika virus in urine. Emerg Infect Dis 2015;21:84-6. http://dx.doi.org/10.3201/eid2101.140894.

8. Foy BD, Kobylinski KC, Foy JLC, et al. Probable non-vector-borne transmission of Zika virus, Colorado, USA. Emerg Infect Dis 2011;17:880-2. http://dx.doi.org/10.3201/eid1705.101939.

9. Musso D, Roche C, Robin E, Nhan T, Teissier A, Cao-Lormeau VM. Potential sexual transmission of Zika virus. Emerg Infect Dis 2015;21:359-61. http://dx.doi.org/10.3201/eid2102.141363.

10. Zanluca C, de Melo VC, Mosimann AL, Dos Santos GI, Dos Santos $\mathrm{CN}$, Luz K. First report of autochthonous transmission of Zika virus in Brazil. Mem Inst Oswaldo Cruz 2015;110:569-72. http://dx.doi. org/10.1590/0074-02760150192.

11. Duffy MR, Chen TH, Hancock WT, et al. Zika virus outbreak on Yap Island, Federated States of Micronesia. N Engl J Med 2009;360:2536-43. http://dx.doi.org/10.1056/NEJMoa0805715. 